\title{
DESENVOLVIMENTO DE UM COPO DE FARINHA DE MANDIOCA COMPOSTÁVEL
}

\author{
DEVELOPMENT OF A COMPOSTABLE GLASS MADE WITH CASSAVA FLOUR
}

\author{
Giorgia Leticia Borgmann \\ Bacharel em Engenharia de Produção \\ Universidade Federal do Paraná - UFPR \\ Curitiba, Paraná - Brasil. \\ borgmanngiorgia@gmail.com \\ Marcell Mariano Corrêa Maceno \\ Doutor em Engenharia de Recursos Hídricos \\ Universidade Federal do Paraná - UFPR \\ Curitiba, Paraná - Brasil. \\ marcell.maceno@ufpr.br \\ Matheus Tavares Lacerda \\ Mestrando em Engenharia de Produção \\ Universidade Federal do Paraná - UFPR \\ Curitiba, Paraná - Brasil. \\ matheus_mtl@hotmail.com \\ Marcelo Vitor Fiatkoski \\ Mestrando em Engenharia de Produção \\ Universidade Federal do Paraná - UFPR \\ Curitiba, Paraná - Brasil. \\ marcelo.fiat72@gmail.com
}

Resumo: Atualmente existe uma alta procura por produtos sustentáveis. Deste modo, é importante o desenvolvimento de novos produtos que atendam a essa demanda. Este trabalho propõe um copo descartável à base de mandioca, em substituição aos copos descartáveis tradicionais de base fóssil. As pesquisas com as biobases têm contribuído para o desenvolvimento de biopolímeros, porém estas não conseguem manter as características físico-mecânicas dos plásticos convencionais, gerando a necessidade de estudos nesta área. Desta forma, foi elaborada uma receita impermeável de modo a atender à função de produto do copo descartável. Para melhor embasamento da aceitação deste produto, foram realizadas pesquisas de análise de mercado através de entrevista usando o Google formulário, avaliação de risco, análise da concorrência comercial e das expectativas dos consumidores. Por fim, foram avaliados os processos industriais necessários para a confecção deste produto. Pôde-se concluir que o copo descartável à base de mandioca proposto atende à função de produto. Entretanto, há a necessidade de melhoria de produto visando a redução de custos, dado que o copo proposto possui um custo elevado se comparado aos copos fabricados a partir do petróleo.

Palavras-chave: Sustentabilidade. Copo descartável. Desenvolvimento de produto.

Abstract: Currently, we have a high demand for sustainable products. Thus, it is essential to develop new products that meet this demand. This work proposes a disposable cup based on cassava, replacing the traditional disposable cups of fossil base. Researchs with biobased have contributed to the development of biopolymers. However, these cannot maintain the physical-mechanical characteristics of conventional plastics, generating the need for better studies in this area. In this way, an impermeable recipe was elaborated in order to fulfill the product function of the disposable cup. For a better basis for accepting this product, market analysis surveys were conducted through interviews using Google form, as well as risk were made evaluation, analysis of commercial competition, and consumer expectations. Finally, the industrial processes necessary for the manufacture of this product were evaluated. It was concluded that the proposed cassava-based disposable cup serves the function of a product. However, there is a need for product improvement in order to reduce costs, as the proposed cup has a high cost compared to cups made from petroleum.

Keywords: Sustainability. Disposable cup. Product development.

\section{Cite como}

American Psychological Association (APA)

Borgmann, G. L., Maceno, M. M. C., Lacerda, M. T., \& Fiatkoski, M. V. (2021, jul./dez.). Desenvolvimento de um copo de farinha de mandioca compostável. Revista Inovação, Projetos e Tecnologias - IPTEC, São Paulo, 9(2), 271-288.

https://doi.org/10.5585/iptec.v9i2.20374. 


\section{Introdução}

A sustentabilidade é um dos temas mais discutidos na atualidade, sendo o descarte inadequado dos resíduos sólidos um problema crescente, devido a fatores como o crescimento populacional e econômico, elevação da industrialização e do consumo e a obsolescência de produtos (LAGO, 2013). Em um estudo realizado pela WWF Brasil (2018), o Brasil é o quarto maior produtor de lixo plástico do mundo, com uma produção de 11,3 milhões de toneladas por ano e, conforme o mesmo estudo, apenas 145 mil toneladas são recicladas por ano, equivalente a $1,28 \%$.

Uma pesquisa realizada pela ONU evidencia que $80 \%$ do lixo dos oceanos é constituído de material plástico; causando, assim, grandes danos ao ecossistema marinho, calculado em mais de 8 bilhões de dólares (Cazarré, 2018). Os copos plásticos descartáveis, amplamente difundidos, também contribuem com impacto ao meio ambiente. Segundo a Associação Brasileira de Empresas de Limpeza Pública e Resíduos, são consumidos 720 milhões de copos descartáveis por dia no Brasil, o que equivale a 1.500 toneladas de resíduos gerados diariamente (ABRELPE - Associação Brasileira das Empresas de Limpeza Pública Estaduais, 2020; Corrêa \& Heemann, 2016).

A produção global de plástico deve aumentar continuamente de 300 milhões de toneladas, em 2015, a 1.800 milhões de toneladas em 2050 (Ryan, 2015). Há grande preocupação com o uso de plásticos de material não renovável, e nessa perspectiva a sociedade, governos e cientistas têm se mobilizado para buscar alternativas que superem os graves problemas causados pelo uso dessa matéria-prima.

Uma alternativa crescente para a não utilização do plástico para a produção de utensílios descartáveis são os materiais comestíveis e compostáveis. Os materiais mais utilizados para a fabricação desses produtos são derivados de algas ou farinhas. Existem três categorias: aqueles extraídos diretamente de matérias-primas naturais, como amido, celulose, proteína e procariotos marinhos; os produzidos por síntese química de monômeros bioderivados; e aqueles produzidos a partir de microrganismos, tais como hidroxibutirato e hidroxivalerato (Fabra et al., 2011).

Os materiais da biobase, portanto, são de origem natural, renováveis, e podem ser extraídos ou produzidos para este fim. Os plásticos biodegradáveis devem ter as características de desempenho necessárias em seus usos pretendidos, mas após o uso devem sofrer biodegradação em resíduos apropriados. Além disso, os biomateriais de base agrícola podem ser usados eficazmente na produção de combustível, produtos químicos, enzimas e alimentos (Galanakis, 2018). 
No mundo existem diversas empresas que já começaram a produção de utensílios descartáveis comestíveis, tais como: Biotrem - empresa polonesa que produz pratos e talheres a partir do trigo; CBPak - empresa brasileira que produz embalagens a partir da farinha de mandioca; e Loliware - empresa americana que produz copos e canudos à base de algas. Contudo, essas iniciativas possuem um preço que não é competitivo com os utensílios descartáveis produzidos de material plástico. Por exemplo, o copo produzido pela empresa Loliware é apenas comercializado em dólar e possui um alto custo, por isso não foi considerado como critério de comparação. Já o copo de farinha de mandioca da empresa distribuidora CBPak Tecnologia custa $\mathrm{R} \$ 0,40$ a unidade, enquanto copos de plástico descartáveis são vendidos pela empresa $M \& B$ embalagens descartáveis a $\mathrm{R} \$ 0,03$ a unidade (Distribuidora $\mathrm{M} \& \mathrm{~B}$ - Embalagens Descartáveis, 2020).

Neste contexto, o objetivo do presente estudo é propor a elaboração de um copo descartável compostável através da utilização de biobases, pois através de uma pesquisa de mercado foi identificado esse interesse pelo meio ambiente dos consumidores.

\section{Referencial teórico}

\subsection{Processo de desenvolvimento de produtos}

O Processo de Desenvolvimento de Produtos (PDP) envolve atividades e decisões que originam um novo produto ou serviço, ou a melhoria em um já existente, desde a ideia inicial até a descontinuação do produto, com a finalidade de sistematizar esse processo. Para isso devese identificar os desejos dos clientes e traduzi-los em especificações a serem desenvolvidas para gerar soluções técnicas e comerciais. O PDP é constituído de várias etapas: das descobertas de novas necessidades do usuário, do desenvolvimento, da avaliação, dos testes e, finalmente, do descarte do produto (Souza, 2016).

Devido às rápidas mudanças tecnológicas, as empresas estão operando em mercados que exigem inovação mais frequente, ciclos de vida de produto mais curtos e em produtos com alta qualidade e confiabilidade. Deste modo, o sucesso das organizações está fortemente ligado ao lançamento de novos produtos (Salgado et al., 2010).

A metodologia de desenvolvimento de produtos, elaborada por Rozenfeld et al. (2006), foi a selecionada para a realização do presente estudo. O modelo consiste numa metodologia mais tradicional para o desenvolvimento de produtos, utilizada em empresas de bens de consumo já estabelecidas no mercado. Para o autor deste método, as atividades do PDP são 
classificadas em três etapas que compreendem o pré-desenvolvimento, o desenvolvimento e o pós-desenvolvimento, conforme apresentado na figura 1 (Rozenfeld et al., 2006).

\section{Figura 1.}

Etapas do Desenvolvimento de Produtos

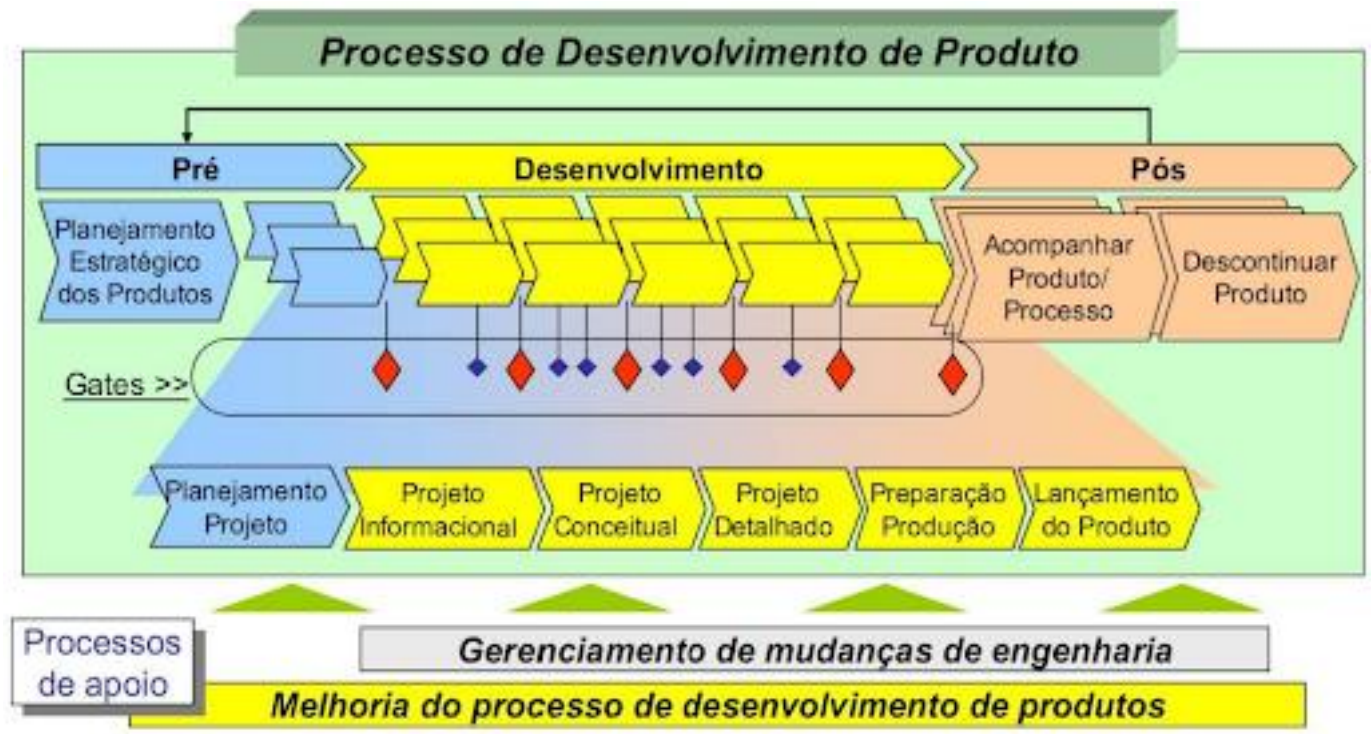

Fonte: Rozenfeld et al. (2006).

Antes de iniciar o desenvolvimento de um novo produto, existe o planejamento estratégico do produto, onde será analisado o planejamento estratégico da empresa e definidos os produtos que podem alcançar os objetivos da empresa.

Pré-desenvolvimento: nesta etapa ocorre o planejamento estratégico do produto, em que será analisado o planejamento estratégico da empresa e definidos os produtos que podem alcançar os objetivos da empresa. Além disso, é definido o produto a ser desenvolvido. Assim sendo, deve-se realizar do projeto o escopo de desenvolvimento, a avaliação econômica, a avaliação de capacidade de risco, a definição de indicadores para monitoramento e definição de planos de negócio (Faria et al., 2008).

Desenvolvimento: esta etapa foca na elaboração do projeto de um produto, podendo ser dividida em quatro etapas. No Projeto Informacional, é feita a aquisição de informações junto aos clientes, como as suas expectativas e necessidades sobre o produto. Na fase de Projeto Conceitual, baseia-se nas informações obtidas na fase de projeto informacional para propor os conceitos que serão adotados no produto. Em seguida é realizado um estudo das funções que serão desempenhadas pelo produto, com a finalidade de atender às necessidades do consumidor. $\mathrm{Na}$ fase de Projeto Preliminar, deve-se conhecer o conceito e a estrutura funcional do produto 
para poder dimensioná-lo, selecionando-se materiais, formas, componentes, processos de fabricação e montagem. Ao final desta fase, os produtos devem ser totalmente estruturados. $\mathrm{Na}$ fase Projeto Detalhado, última etapa do desenvolvimento, a disposição, a forma, as dimensões e as tolerâncias dos componentes são finalmente determinadas. Com todos esses estudos realizados e mapeados é possível realizar o lançamento do produto desenvolvido (Faria et al., 2008).

Pós-desenvolvimento: nesta fase ocorre o planejamento de como o produto será acompanhado e retirado do mercado no fim do seu ciclo de vida. Definem-se as equipes e os recursos necessários para as alterações de engenharia, visando corrigir e aperfeiçoar a experiência que o cliente terá com o consumidor. Nesta etapa também são realizados estudos para verificar quando esse produto deve ser retirado do mercado (Faria et al., 2008).

No presente estudo, foi utilizado uma versão simplificada desse método de desenvolvimento de produto, visto que não se trata de uma empresa já estruturada no mercado e ser um produto inovador. Deste modo, as fases que serão abordadas, de maneira simplificada, nesse estudo são a de pré-desenvolvimento e desenvolvimento.

\section{Metodologia}

O presente estudo é caraterizado como de natureza aplicada, visto que busca gerar conhecimentos com aplicação prática direcionada à solução de um problema específico (Silva \& Menezes, 2001). O objetivo deste estudo tem caráter exploratório, proporcionando maior familiaridade com o determinado assunto, para maior conhecimento ou para construir hipóteses (Gil, 2002). Pode-se ainda classificar como estudo de caso, pois realizou uma análise aprofundada ao empregar múltiplos instrumentos de coleta e análise de dados (Yin, 2001). Estudos de caso visam esclarecer as razões pelas quais decisões foram tomadas, como foram implementadas e qual o resultado obtido (Yin, 2001). Este estudo enquadra-se como quantitativo, baseando-se na investigação por meio da utilização de variáveis mensuráveis e suposições prováveis (Gil, 2002).

Para a estruturação deste estudo, a pesquisa foi desenvolvida em cinco etapas, conforme demonstrado na figura 2. Primeiramente foi elaborado um estudo de prédesenvolvimento do produto. Na segunda etapa, foi desenvolvida uma receita para a constituição do copo descartável. Em seguida, foram estudadas formas de conformação. Durante a quarta etapa, elaborou-se o processo de produção industrial. Para finalizar, na quarta etapa, realizou-se uma análise de custo da matéria-prima deste produto. 


\section{Figura 2.}

Etapas do Desenvolvimento da Pesquisa

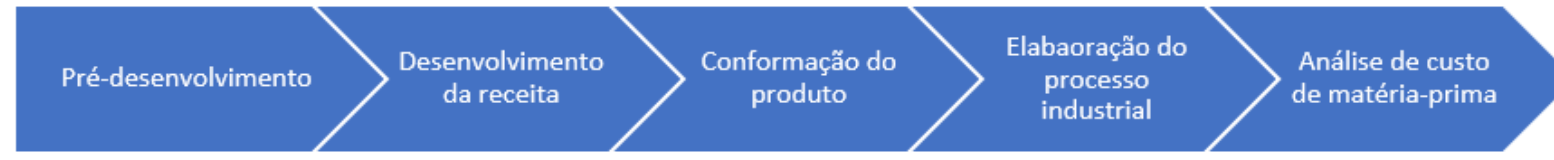

Fonte: Autores (2020).

No pré-desenvolvimento, primeiramente, foi realizada uma análise do mercado brasileiro através de estatísticas da economia e do setor. Em seguida foi realizada uma análise de risco, através do uso da ferramenta SWOT (Strengths, Weaknesses, Opportunities, and Threats) e FMEA (Failure Modes and Effects Analysis). Posteriormente elaborou-se uma análise de concorrência e produtos similares, na qual foi embasada com a ferramenta das 5 forças de Porter (Porter, 2005) e na pesquisa em sites dos competidores sobre os seus produtos. Por fim, uma pesquisa de mercado através do Google formulários, com possíveis consumidores, foi conduzida para entender às necessidades dos clientes através de formulários online.

Em prol do desenvolvimento deste produto, posterior à pesquisa relacionada aos concorrentes, concluiu-se que as matérias-primas mais utilizadas eram à base de algas ou farinhas. Para a elaboração da receita deste estudo, optou-se pela utilização de um copo à base de farinha de mandioca, visto que possui um preço mais competitivo em relação às gelatinas e permite a valorização de ingredientes locais. Para a sua elaboração, foram definidos os produtos utilizados para a execução de testes de maneira empírica e utilizou-se uma balança com precisão de $0,1 \mathrm{~g}$. Inicialmente foram feitos testes em formatos retangulares para avaliar a resistência do material quando assado. Em seguida, iniciaram-se os testes com conformação em forma de copos para testar a impermeabilidade do material.

Os procedimentos para a elaboração da receita do copo compostável foram devidamente padronizados e repetidos cerca de 50 vezes com pequenas variações até encontrar a receita ideal. A partir da receita estabelecida, iniciou-se a segunda etapa do estudo, com o intuito de aprimorar a conformação do copo. Foram testados três modos de conformação: 1) colocando a massa no interior do molde; 2) envolvendo a massa no exterior do molde; 3) envolvendo a massa no exterior do molde e com uma camada de alumínio ao redor para uma transmissão do calor mais homogênea quando assado.

O teste de tempo de compostagem, assim como de validade do produto, também foi realizado nesta etapa do estudo. $\mathrm{O}$ teste de compostagem foi realizado com uma composteira caseira, sendo verificado a cada dois dias o andamento da decomposição do copo. Já o teste de 
validade do produto foi realizado através da análise visual ao longo do tempo, quanto à presença de bolor.

$\mathrm{Na}$ terceira etapa, foram pesquisados equipamentos que poderiam ser adaptados para a produção em escala industrial. Para a finalização deste estudo, foram realizados orçamentos para calcular o custo de matéria-prima do protótipo.

\section{Resultados e discussões}

\subsection{Análise de mercado}

O setor de plástico no Brasil produziu 6,1 milhões de toneladas e teve o faturamento de R\$ 68,8 bilhões em 2017 (IPEA - Instituto de Pesquisa Econômica Aplicada, 2019). Segundo a Associação brasileira de embalagens (ABRE), o faturamento neste setor, em 2019, chegou a $\mathrm{R}$ \$ 80,2 bilhões, um aumento de 3\% em relação ao ano anterior. A indústria de plástico, deste segmento, é a que mais emprega, totalizando em dezembro de 2019118.398 empregos formais, correspondendo a 53\% do total de postos de trabalho do setor (ABRE - Associação Brasileira de Embalagens, 2019).

O setor de alimentos e bebidas é responsável pelo consumo de cerca de $25 \%$ de todo o plástico com produtos com ciclo de vida inferior a um ano (Associação Brasileira da Indústria do Plástico, 2019).

Em contrapartida a esses dados de crescimento, existe um forte movimento para a utilização de materiais com menor impacto ambiental. O senado brasileiro possui um projeto de lei 2928/19 que visa proibir a fabricação, importação e comercialização de sacolas, pratos, copos e talheres plásticos (Lima, 2019). Entretanto, ainda não existe definição legislativa sobre o tema.

\subsection{Avaliação de risco}

Através da ferramenta SWOT é possível estabelecer as forças, fraquezas, oportunidades e ameaças para esse produto. A figura 3 apresenta a síntese para o produto desse estudo. 


\section{Figura 3.}

Resultado da Matriz SWOT Para o Produto em Estudo

\begin{tabular}{|c|c|}
\hline $\begin{array}{l}\text { FORÇAS } \\
\text { - } \quad \text { Foco no mercado } \\
\text { - } \\
\text { - } \quad \text { Cualidade do produto } \\
\end{array}$ & $\begin{array}{l}\text { FRAQUEZAS } \\
\text { - } \quad \text { Falta de domínios do processo produtivo } \\
\text { - } \quad \text { Falta de posicionamento no mercado } \\
\text { - } \quad \text { Capacidade de financiar o produto } \\
\end{array}$ \\
\hline $\begin{array}{l}\text { OPORTUNIDADES } \\
\text { - Consciência ambiental e sustentabilidade } \\
\text { - } \quad \text { Aumento do público alvo } \\
\text { - Crescimento do setor de alimentos } \\
\end{array}$ & $\begin{array}{l}\text { AMEAÇAS } \\
\text { - } \quad \text { Mercado de consumo instável } \\
\text { - } \quad \text { Cultura de utilização de embalagens plásticas }\end{array}$ \\
\hline
\end{tabular}

Fonte: Autores (2020).

Em seguida foi utilizada a ferramenta FMEA, a qual define a necessidade de alterações no projeto do produto, estabelece prioridades para as ações de melhoria, auxilia na definição de testes e validação, na identificação de características críticas e na avaliação dos requisitos e alternativas do projeto, conforme demonstrado no quadro 1.

Através da análise de mercado e da utilização das ferramentas de SWOT e FMEA, foi possível entender a situação desta categoria de produto no mercado, as restrições e os pontos de priorização que devem ser considerar para o desenvolvimento de um novo copo descartável com base biológica.

\section{Quadro 1.}

FMEA Para o Produto em Estudo

\begin{tabular}{|c|c|c|c|c|c|}
\hline Severidade & 16 & 10 & 8 & 5 & 4 \\
\hline $\begin{array}{l}\text { Descrição do } \\
\text { risco }\end{array}$ & $\begin{array}{l}\text { Fragilidade do } \\
\text { copo }\end{array}$ & $\begin{array}{l}\text { Impermeabilidade do } \\
\text { copo }\end{array}$ & Alto custo & $\begin{array}{l}\text { Aceitação do } \\
\text { produto }\end{array}$ & $\begin{array}{l}\text { Capacidade de } \\
\text { financiar o } \\
\text { produto }\end{array}$ \\
\hline Ocorrência & 4 & 2 & 2 & 1 & 1 \\
\hline Impacto & 4 & 5 & 5 & 5 & 4 \\
\hline $\begin{array}{l}\text { Descrição do } \\
\text { impacto }\end{array}$ & $\begin{array}{l}\text { Impacto na } \\
\text { resistência, } \\
\text { comprometendo } \\
\text { a qualidade do } \\
\text { produto }\end{array}$ & $\begin{array}{l}\text { Impermeabilidade do } \\
\text { copo leva ao não } \\
\text { funcionamento do } \\
\text { produto e } \\
\text { inviabilidade de uso }\end{array}$ & $\begin{array}{c}\text { Baixo ou } \\
\text { nenhuma } \\
\text { margem de } \\
\text { lucro, devido } \\
\text { ao alto custo }\end{array}$ & $\begin{array}{l}\text { Baixo índice } \\
\text { de vendas }\end{array}$ & $\begin{array}{l}\text { Inviabilidade de } \\
\text { realizar o projeto }\end{array}$ \\
\hline Ação & Mitigar & Prevenir & Mitigar & Mitigar & Prevenir \\
\hline $\begin{array}{l}\text { Descrição da } \\
\text { ação }\end{array}$ & $\begin{array}{l}\text { Avaliação do } \\
\text { processo e da } \\
\text { receita do copo }\end{array}$ & $\begin{array}{l}\text { Testar o design dos } \\
\text { blocos }\end{array}$ & $\begin{array}{l}\text { Redução dos } \\
\text { custos através } \\
\text { da otimização } \\
\text { dos processos } \\
\end{array}$ & $\begin{array}{c}\text { Campanha } \\
\text { publicitária e } \\
\text { pivotar a ideia }\end{array}$ & $\begin{array}{l}\text { Campanha de } \\
\text { financiamento } \\
\text { coletivo }\end{array}$ \\
\hline Responsável & $\begin{array}{l}\text { Manufatura e } \\
\text { qualidade }\end{array}$ & $\begin{array}{l}\text { Engenharia do } \\
\text { produto }\end{array}$ & $\begin{array}{l}\text { Engenharia de } \\
\text { processo }\end{array}$ & $\begin{array}{l}\text { Marketing e } \\
\text { design do } \\
\text { produto }\end{array}$ & Financeiro \\
\hline
\end{tabular}

Fonte: Autores (2020). 


\subsection{Análise de concorrência e produtos similares}

Para a avaliação da concorrência, foi utilizada a ferramenta das 5 forças de Porter, para melhor análise da competitividade desse segmento de mercado. Os dados de entrada consideraram o conceito de solução compostável, fabricado a partir de matéria-prima renovável. A análise dos dados permitiu chegar aos resultados expressos no quadro 2.

Neste sentido é possível verificar que existe uma tendência de novos produtos com viés sustentável para esta função (copo descartável); contudo, o mercado, considerando fornecedores e clientes, ainda está em estruturação devido à própria novidade dos produtos.

\section{Quadro 2.}

5 Forças de Porter Considerando o Escopo de Produto em Estudo

\begin{tabular}{|l|l|l|}
\hline \multicolumn{1}{|c|}{ Item analisado } & Resultado & \multicolumn{1}{|c|}{ Justificativas levantadas } \\
\hline Ameaça de novos entrantes & Alto & $\begin{array}{l}\bullet \text { Tendência de migração para soluções } \\
\text { sustentáveis. }\end{array}$ \\
\hline Poder de barganha com fornecedores & Baixo & $\begin{array}{l}\bullet \text { Baixo volume de compras; } \\
\bullet \text { Grande quantidade de fornecedores. }\end{array}$ \\
\hline Concorrência & Baixo & $\begin{array}{l}\bullet \text { Poucas empresas com a tecnologia } \\
\text { desenvolvida. }\end{array}$ \\
\hline Poder de barganha com consumidores & Baixo & $\begin{array}{l}\bullet \text { Volume de compra baixo; } \\
\bullet \text { Lucro baixo. }\end{array}$ \\
\hline Ameaça de substitutivos & Baixo & $\begin{array}{l}\bullet \text { Concorrentes diretos e indiretos; } \\
\bullet \text { Inovação e novas tecnologias; } \\
\bullet \text { Fidelização dos clientes. }\end{array}$ \\
\hline
\end{tabular}

Fonte: Autores (2020).

\subsection{Requisitos dos clientes}

Para a efetivação da pesquisa, utilizou-se o método de entrevista tendo como base um questionário de múltipla escolha, com perguntas previamente elaboradas, através do Google forms. Os respondentes indicaram idade, se têm preocupação com o consumo sustentável, quantas unidades de copos descartáveis utilizam por dia e se já utilizam canudos descartáveis, reafirmando a preocupação com a sustentabilidade, conforme apêndice 1.

Através dessa pesquisa, percebeu-se que o custo, qualidade e meio ambiente são aspectos que o consumidor preza ao realizar compras. Quanto ao consumo de copos descartáveis, evidenciou-se que: 39,5\% não consomem copos descartáveis; 20,2\% consomem 
1 copo por dia; $13,2 \%$ consomem 2 copos por dia; $13,6 \%$ consomem 3 copos por dia; 2,2\% consomem 4 copos por dia; $11,4 \%$ consomem 5 ou mais copos por dia.

A pesquisa apontou que a maioria considera os aspectos ambientais das marcas que consomem. Deste modo, pode-se perceber que existe uma abertura para produtos mais sustentáveis, mas que eles devem ainda ser competitivos no preço para uma melhor aceitação no mercado. Os dados podem ser observados na figura 4, onde a pergunta tomou em consideração o consumo sustentável.

\section{Figura 4.}

\section{Questionário (pergunta 2)}

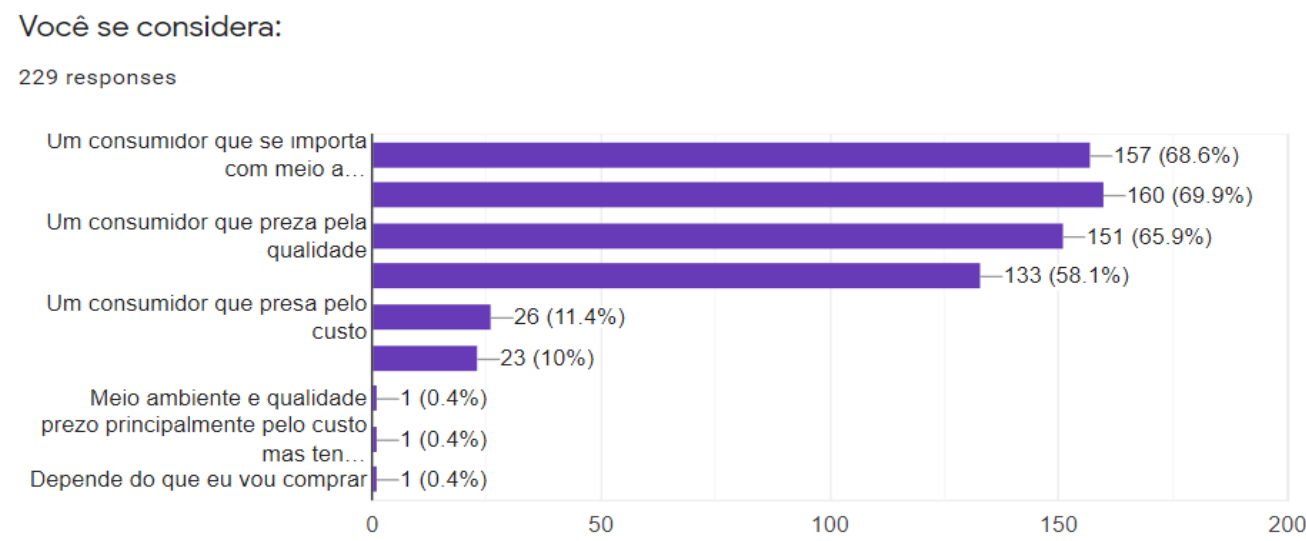

Fonte: Autores (2020).

\subsection{Escopo do projeto}

A premissa principal do produto é criar um copo que possa ser descartado como matéria orgânica e também seja compostável. Para tal, o mecanismo definido foi a utilização de matéria orgânica na sua composição. O protótipo do copo possui as medidas estabelecidas conforme o quadro 3.

Quadro 3.

Medidas do produto

\begin{tabular}{|c|c|}
\hline Dimensões & Medida $(\mathbf{c m})$ \\
\hline Diâmetro da base & 4 \\
\hline Diâmetro superior & 5 \\
\hline Altura & 10 \\
\hline
\end{tabular}

Fonte: Autores (2020). 
Os copos devem atender às condições de fabricação de alimentos estabelecidas pela vigilância sanitária; além disso, assegurar as especificidades estabelecidas pela norma brasileira para Copos Plásticos Descartáveis - NBR 14.865, publicada em 2012, tendo definidos os critérios mínimos para assegurar a qualidade do produto oferecido ao consumidor (ABNT Associação Brasileira de Normas Técnicas, 2012).

\subsection{Elaboração da receita}

Primeiramente levantaram-se os materiais mais comumente utilizados por empresas presentes nesse mercado. Estes eram à base de gelatinas ou farinhas. Optou-se por elaborar um copo à base de farinha de mandioca, visto que é um ingrediente local e com custo acessível. Para esse estudo, foram elaboradas duas receitas, conforme é demonstrado no quadro 4, com a proporção de cada insumo utilizado para a elaboração do copo.

\section{Quadro 4.}

Receitas dos Copos Compostáveis

\begin{tabular}{|l|l|l|}
\hline Insumo & Receita 1 & Receita 2 \\
\hline Farinha de mandioca & $50 \%$ & $40 \%$ \\
\hline Amido de mandioca & $20 \%$ & $25 \%$ \\
\hline Farinha de casca de banana verde & - & $5 \%$ \\
\hline Água & $30 \%$ & $30 \%$ \\
\hline
\end{tabular}

Fonte: Autores (2020).

Nessa primeira etapa, chegou-se à conclusão de que o protótipo do copo seria fabricado em três etapas: fabricação da massa, conformação e cozimento no forno.

A fabricação da massa consistiu em misturar primeiramente os ingredientes secos, farinha de mandioca e amido de mandioca, farinha de casca de banana verde e em seguida adicionar a água. A consistência da massa ficou granulada e úmida. Com a adição de farinha de casca de banana verde, aproveita-se um resíduo e isso pode ser utilizado para a promoção do produto.

Para os primeiros testes, foram conformados em chapas para testar apenas a consistência e resistência da massa. Em seguida foram utilizadas formas de cupcakes de metal para conformar em formato aproximado de um copo. A etapa de assar a massa utilizou um forno residencial à temperatura de $180^{\circ} \mathrm{C}$ por 60 minutos, o cozimento deve ser conduzido lentamente para evitar a formação de bolhas. 


\subsection{Melhoria de conformação do produto}

O objetivo dessa etapa do estudo foi aprimorar a conformação do protótipo e testar parâmetros importantes na comercialização, como a validade e o tempo de compostagem. Foram testadas diversas formas de conformação. As primeiras tentativas foram conduzidas, colocando-se a massa no interior do copo inox, contudo o interior do copo compostável ficou ressecado e foi necessário colocar um impermeabilizante, testando-se a gelatina sem sabor. Em seguida tentou-se envolver o copo com a massa. Neste modo de conformação, não foi necessário fazer a etapa de impermeabilização, visto que quando o material assa em contato com o metal, o calor é transmitido de maneira uniforme e cria-se uma película que impermeabiliza a massa, entretanto a parte externa do copo ficou ressecada. A maneira que resultou no melhor protótipo foi o envolvimento do copo de alumínio com a massa e em seguida envolver a massa com três camadas de papel alumínio. Desta forma, o calor foi transmitido mais uniformemente para os dois lados do copo.

Para o teste de validade, foi deixado um copo dentro de um saco plástico. O parâmetro para validar que o copo não estava mais em condições de uso foi a aparição de bolor e, pelo período de 6 meses, não foi possível determinar visualmente a presença de nenhum fungo.

$\mathrm{O}$ teste de tempo de compostagem foi feito em uma compoteira caseira, sendo o tempo estimado para o início da compostagem em 24 dias.

\subsection{Processo de fabricação em escala industrial}

Para a fabricação desse produto em escala industrial, seriam necessárias as seguintes etapas demonstradas na figura 5 .

\section{Figura 5.}

Etapas da Escala Industrial

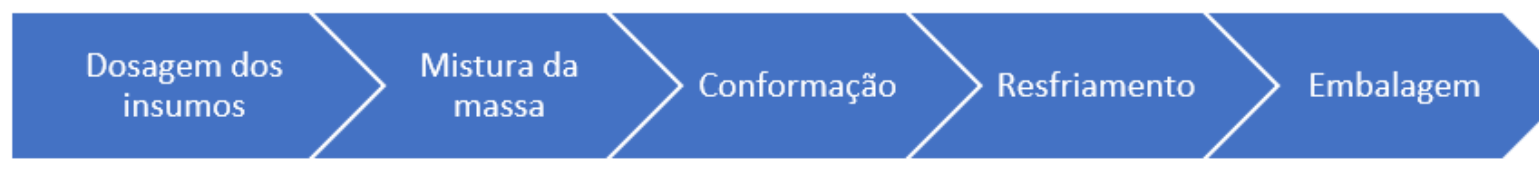

Fonte: Autores (2020).

Para a etapa de mistura de massa, seria necessário um misturador horizontal de massas industrial, que deixe a massa granulada para facilitar o transporte, através de roscas infinitas até a conformação. 
No processo de conformação, a primeira etapa é a dosagem da massa nos moldes. Em seguida, uma prensa quente deve conformar o copo. Os moldes devem ser compostos de dois lados metálicos capazes de formar o copo com uma espessura adequada. Seria necessário fazer uma adaptação de uma prensa de conformação a quente para as necessidades desse produto. Assim, através desse modo de conformação, não seria necessária a etapa de impermeabilização. Em seguida, os copos devem passar por uma etapa de resfriamento, através de uma esteira refrigerada para evitar que seja embalado a quente.

$\mathrm{O}$ processo de embalagem seria efetuado numa embaladora que efetua igualmente a contagem dos copos. O material utilizado para embalar os conjuntos de copos pode ser composto por plástico biodegradável, para ser congruente com a proposta desse produto.

\subsection{Custo de matéria-prima}

Para a estimativa do custo de matéria-prima, foi considerado que o peso total de um copo de $30 \mathrm{~g}$ e os custos por quilo de cada ingrediente foi estipulado segundo preços divulgados pelos produtores. Os valores estão expressos no quadro 5 para a receita 1 e no quadro 6 para a receita 2.

\section{Quadro 5.}

Custo de Matérias-Primas Para a Receita 2

\begin{tabular}{|l|l|l|l|}
\hline RECEITA 1 & Custo $(\mathbf{R} \$ \mathbf{k g})$ & Percentual do produto & Custo de 1 unidade \\
\hline Farinha de mandioca & 3,00 & $50 \%$ & $\mathrm{R} \$ 0,05$ \\
\hline Amido de mandioca & 6,00 & $20 \%$ & $\mathrm{R} \$ 0,04$ \\
\hline Água & 0,01 & $30 \%$ & $\mathrm{R} \$ 0,00$ \\
\hline TOTAL & - & $\mathbf{1 0 0 \%}$ & $\mathbf{R} \mathbf{0 , 0 9}$ \\
\hline
\end{tabular}

Fonte: Autores (2020).

\section{Quadro 6.}

Custo de Matérias-Primas Para a Receita 2

\begin{tabular}{|l|l|l|l|}
\hline RECEITA 2 & Custo $(\mathbf{R} \$ / \mathbf{k g})$ & Percentual do produto & Custo de 1 unidade \\
\hline Farinha de casca de banana verde & $\mathrm{R} \$ 16,50$ & $5 \%$ & $\mathrm{R} \$ 0,02$ \\
\hline Farinha de mandioca & 3,00 & $40 \%$ & $\mathrm{R} \$ 0,05$ \\
\hline Amido de mandioca & 6,00 & $25 \%$ & $\mathrm{R} \$ 0,04$ \\
\hline Água & 0,01 & $30 \%$ & $\mathrm{R} \$ 0,00$ \\
\hline
\end{tabular}




\begin{tabular}{|l|l|l|l|}
\hline RECEITA 2 & Custo $(\mathbf{R} \$ / \mathbf{k g})$ & Percentual do produto & Custo de $\mathbf{1}$ unidade \\
\hline TOTAL & - & $100 \%$ & $\mathrm{R} \$ 0,11$ \\
\hline
\end{tabular}

Fonte: Autores (2020).

\section{Conclusões}

Devido à tendência de mudança nos valores culturais dos consumidores, que buscam produtos sustentáveis, é possível observar uma oportunidade para a introdução de produtos com essa característica.

Através desse estudo foi possível analisar e desenvolver um protótipo com menor impacto ambiental, visto que é possível fabricar este copo descartável a partir de matéria orgânica renovável. A partir das análises realizadas, verificou-se que esse copo atende às necessidades e expectativas dos clientes, assim como se adéqua às legislações de controle de produção de resíduos e às normas sanitárias estabelecidas.

Entretanto houve algumas limitações no desenvolvimento deste estudo. Em primeiro lugar, os processos industriais descritos nesta pesquisa são apontamentos iniciais para a sua produção em escala industrial. Com isso, é necessário um refinamento desses processos de modo a torná-lo mais competitivo. Outra limitação foi que, com a estimativa de preços das matérias-primas, os copos compostáveis apresentaram um custo maior do que os copos plásticos tradicionais, caracterizando a necessidade de melhoria de design do produto no sentido de redução de massa, e também dos processos de fabricação para produção em larga escala.

Por fim, conclui-se que a utilização dos plásticos de origem fóssil traz muitos prejuízos ao meio ambiente, aumentando o número de pesquisas em escala global, na tentativa de substituição dessa categoria de produto por copos compostáveis que, por sua vez, esbarram na falta de tecnologia, no incentivo à produção e em questões como custo de tal produção.

Neste sentido, com base nos documentos inventariados, pode-se prever para futuros estudos a necessidade da realização de pesquisas na intenção de desenvolver uma receita competitiva aos copos descartáveis tradicionais. Este estudo apresenta um primeiro passo na criação de copos compostáveis competitivos, entretanto futuros estudos devem focar na manutenção das características de compostabilidade e renovabilidade do copo, paralelamente com a redução dos custos dos copos compostáveis, visando a torná-los competitivos no mercado. 


\section{Referências}

ABNT - Associação Brasileira de Normas Técnicas. (2012). ABNT NBR 14865: Copos plásticos descartáveis.

ABRE - Associação Brasileira de Embalagens. (2019). ESTUDO ABRE MACROECONÔMICO DA EMBALAGEM E CADEIA DE CONSUMO. https://www.abre.org.br/dados-do-setor/ano2019/

ABRELPE - Associação Brasileira das Empresas de Limpeza Públicas Estaduais. (2020). PANORAMA DOS RESÍDUOS SÓLIDOS NO BRASIL 2020. https://abrelpe.org.br/panorama-2020/

Associação Brasileira da Indústria do Plástico. (2019). Perfil 2019. ABIPLAST. http://www.abiplast.org.br/wp-content/uploads/2020/09/Perfil_2019_web_abiplast.pdf

Cazarré, M. (2018). Poluição do plástico é desafio para o Dia Mundial do Meio Ambiente. https://agenciabrasil.ebc.com.br/internacional/noticia/2018-06/acabar-com-poluicaodo-plastico-e-tema-do-dia-mundial-do-meio-ambiente

Corrêa, M. E. R. M., \& Heemann, A. (2016). PROPOSTA DE SUBSTITUIÇÃO DE COPOS PLÁSTICOS DESCARTÁ VEIS EM FÁBRICA DE GRANDE PORTE. In MIX Sustentável (Vol. 2, Issue 2).

http://ojs.sites.ufsc.br/index.php/mixsustentavel/article/view/1430

Distribuidora M\&B - Embalagens Descartáveis. (2020). Copos Descartaveis - embalagens descartáveis em geral. https://www.mbembalagens.com.br/copos-descartaveis

Fabra, M. J., Pérez-Masiá, R., Talens, P., \& Chiralt, A. (2011). Influence of the homogenization conditions and lipid self-association on properties of sodium caseinate based films containing oleic and stearic acids. Food Hydrocolloids, 25(5), 1112-1121. https://doi.org/10.1016/j.foodhyd.2010.10.008

Faria, A. F. de, Pinto, A. C. de A., Ribeiro, M. N., Cardoso, T. S., \& Ribeiro, J. P. C. (2008). PROCESSO DE DESENVOLVIMENTO DE NOVOS PRODUTOS: UMA EXPERIÊNCIA DIDÁTICA. Enegep 2008. http://www.abepro.org.br/biblioteca/enegep2008_tn_stp_073_521_12155.pdf

Galanakis, C. M. (2018). Phenols recovered from olive mill wastewater as additives in meat products. In Trends in Food Science and Technology (Vol. 79, pp. 98-105). Elsevier Ltd. https://doi.org/10.1016/j.tifs.2018.07.010

Gil, A. C. (2002). Como elaborar projetos de pesquisa (4th ed.). Atlas.

IPEA - Instituto de Pesquisa Econômica Aplicada. (2019). Visão Geral | Carta de Conjuntura. https://www.ipea.gov.br/cartadeconjuntura/index.php/category/sumarioexecutivo/

LAGO, S. M. S. (2013). Reverse logistics, legislation and sustainability: a model for collecting residual frying oil as feedstock for biodiesel production. Universidade 
Estadual do Oeste do Paraná, Toledo.

Lima, L. (2019, July 23). Proposta proíbe sacola, prato, copo e talher de plástico - Notícias Portal da Câmara dos Deputados. https://www.camara.leg.br/noticias/563216proposta-proibe-sacola-prato-copo-e-talher-de-plastico

Porter, M. E. (2005). Estrategia Competitiva. In Estratégia competitiva (1st ed.). GEN Atlas. Rozenfeld, H., Forcellini, F. A., Amaral, dDniel C., Alliprandini, D. H., \& Scalice, R. K. (2006). GESTÃO DE DESENVOLVIMENTO DE PRODUTOS: UMA REFERÊNCIA PARA A MELHORIA DO PROCESSO. Saraiva.

Ryan, P. G. (2015). A brief history of marine litter research. In Marine Anthropogenic Litter (pp. 1-25). Springer International Publishing. https://doi.org/10.1007/978-3-31916510-3_1

Salgado, E. G., Salomon, V. A. P., Mello, C. H. P., Fass, F. D. M., \& Xavier, A. F. (2010). MODELOS DE REFERENCIA PARA DESENVOLVIMENTO DE PRODUTOS: CLASSIFICAÇÃO, ANÁLISE E SUGESTÕES PARA PESQUISAS FUTURAS. Produção Online, 10(4), 886-911.

Silva, E. L. da, \& Menezes, E. M. (2001). Metodologia da pesquisa e elaboração de dissertação.

Souza, A. J. S. (2016). Design como forma de inovação no processo de desenvolvimento de produtos (PDP) e seus conceitos metodológicos. Di Factum.

WWF Brasil. (2018). RELATÓRIO PLANETA VIVO 2018: Uma ambição maior. https://www.wwf.org.br/natureza_brasileira/especiais/relatorio_planeta_vivo_2018/

Yin, R. K. (2001). Estudo de Caso: Planejamento e Método (2nd ed.). Bookman. 


\section{Apêndice 1}

\section{Questionário de pesquisa}

\section{Pergunta 1}

Quantos anos você tem?

228 responses

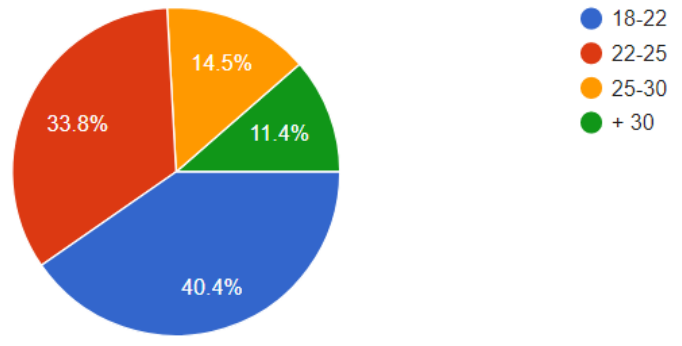

\section{Pergunta 2}

Você se considera:

229 responses

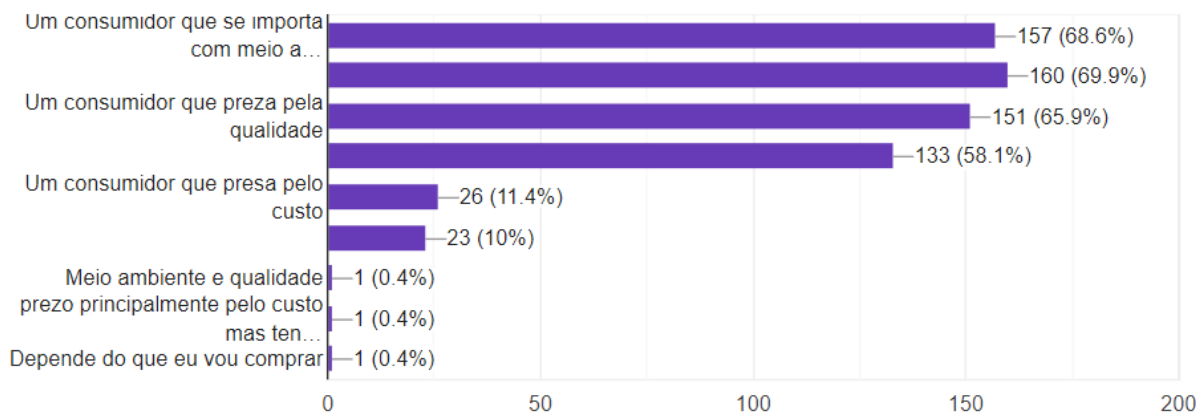

\section{Pergunta 3}

Você se informa sobre o impacto ambiental das marcas que você consome?

225 responses

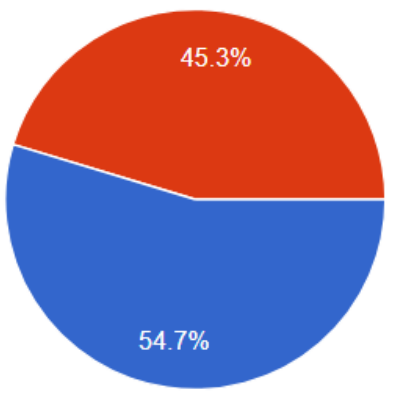




\section{Pergunta 4}

Quantos copos plásticos descartáveis você consome por dia?

228 responses

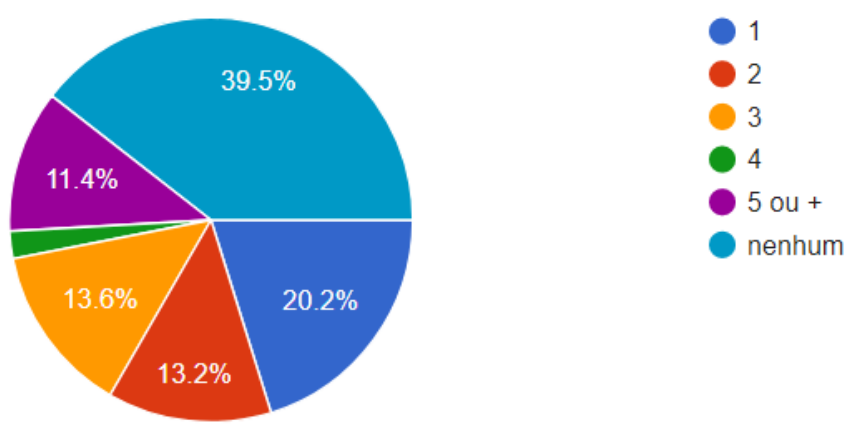

\section{Pergunta 5}

Você utiliza canudos reutilizáveis?

230 responses

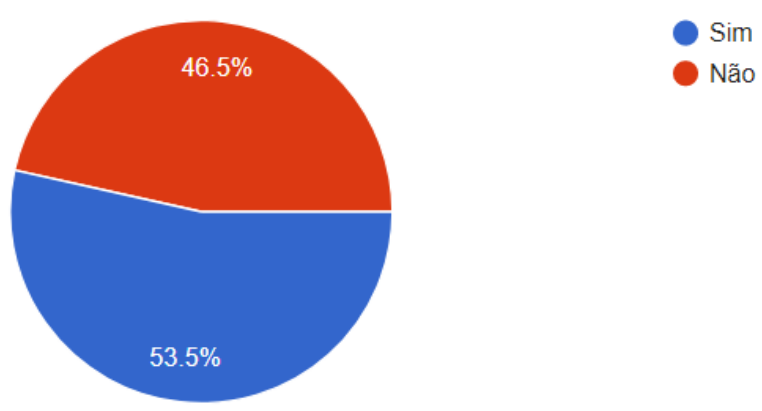

